MIDAS

Museus e estudos interdisciplinares

$7 \mid 2016$

Varia

\title{
O museu como laboratório: Análise da exposição VI Jovem Arte Contemporânea
}

The museum as a laboratory: Analysis of the exhibition VI Jovem Arte

Contemporânea

Heloisa Olivi Louzada

\section{OpenEdition}

\section{Journals}

Edição electrónica

URL: http://journals.openedition.org/midas/1130

DOI: $10.4000 /$ midas. 1130

ISSN: 2182-9543

\section{Editora:}

Alice Semedo, Paulo Simões Rodrigues, Pedro Casaleiro, Raquel Henriques da Silva, Ana Carvalho

\section{Refêrencia eletrónica}

Heloisa Olivi Louzada, «O museu como laboratório: Análise da exposição VI Jovem Arte

Contemporânea », MIDAS [Online], 7 | 2016, posto online no dia 29 novembro 2016, consultado no dia

19 abril 2019. URL : http://journals.openedition.org/midas/1130 ; DOI : 10.4000/midas.1130

Este documento foi criado de forma automática no dia 19 Abril 2019.

\section{cc) (†) (อ)}

Midas is licensed under a Creative Commons Attribution-NonCommercial-ShareAlike 3.0 International License 


\section{O museu como laboratório: Análise da exposição VI Jovem Arte Contemporânea}

The museum as a laboratory: Analysis of the exhibition VI Jovem Arte

Contemporânea

Heloisa Olivi Louzada

\section{NOTA DO EDITOR}

Artigo recebido a 29.03.2015

Aprovado para publicação a 18.12.2015

$1 \quad \mathrm{O}$ artigo assume como ponto de partida metodológico os estudos sobre história das exposições realizados por Altshuler (2008) e o estudo sobre o Museu de Arte Contemporânea da Universidade de São Paulo (MAC USP), com foco na coleção de arte conceitual adquirida durante a gestão de Walter Zanini (1963-1977), da autoria de Freire (1999). Defende-se a relevância do estudo das exposições para a ampliação do campo da discussão da história da arte, da museologia e dos estudos curatoriais, agregando elementos políticos e sociais que procuram compreender e discutir as formas de circulação, os circuitos de legitimação e os enquadramentos institucionais que envolvem as diversas instâncias do campo artístico. Esta metodologia de estudo compreende uma análise que tem como fundamento o entendimento da arte e do meio artístico como agentes ativos no contexto político e social.

2 As exposições são um local privilegiado para a análise da construção institucional da história da arte, pois é nesse contexto que se encontram diversos aspectos que permeiam a sua construção, para além das obras vistas de forma isolada. Na exposição, as obras apresentadas dentro de um discurso curatorial, que envolve a disposição espacial das obras, a cor das paredes, a luminosidade, a presença ou não de textos de parede, além da 
seleção de obras e de artistas, que são sempre escolhas pautadas por determinadas visões da história e de arte, que incluem, excluem e qualificam através desse discurso visual determinadas escolas, artistas ou estilos.

3 A inclusão do estudo dos objetivos que guiam a criação de cada museu e dos seus acervos, bem como a forma de exibi-los e de adquiri-los, e a investigação sobre as figuras fundadoras e dos diretores de museu pode acrescentar elementos para a escrita de uma história da arte que tem em conta as relações políticas, sociais e económicas que influenciam o discurso curatorial, a museologia, a construção de acervos e a forma de atuação do museu em determinado contexto social e político. Assim sendo, as exposições tomadas como objeto de estudo alargam o campo da história da arte ao adicionar elementos arquitetónicos, visuais e políticos que pautam e influenciam a produção artística e as narrativas da história da arte.

Not only does looking at exhibitions reveal previously ignored works and enlarge the cast of characters beyond the established players, it adds to the descriptive explanatory mix a range of social, economic and political factors. And provides a vehicle for setting the objects of art history within broader regimes of perception and values. (Altshuler 2008, 10)

Neste sentido, propõe-se uma reflexão sobre a VI Exposição Jovem Arte Contemporânea (daqui em diante VI JAC) realizada no Museu de Arte Contemporânea da Universidade de São Paulo (MAC USP) em 1972. Esta exposição pode ser considerada um marco na história do museu, das exposições de arte e na forma como estas são concebidas, inclusive a nível internacional, já que, como se verá adiante, Walter Zanini (1963-1978), diretor do museu à época, estava em constante troca e diálogo com diretores de museus de várias partes do mundo, discutindo sobre o papel dos museus e compartilhando as experiências que se vinham fazendo no MAC USP, desde o final da década de 1960. A VI JAC, como ficou conhecida, é o fruto direto desse diálogo estabelecido do MAC USP com outros museus de arte moderna e contemporânea a nível internacional durante a gestão de Walter Zanini.

O MAC USP foi fundado em 1963, a partir da doação total do acervo do Museu de Arte Moderna de São Paulo para a Universidade de São Paulo. Walter Zanini assumiu a direção do museu e, aos poucos, começou, juntamente com jovens artistas e professores da Universidade de São Paulo, a dar forma a um novo projeto de museu.

Durante os primeiros anos na direção do MAC USP, Zanini concentrou os seus esforços no preenchimento das lacunas e na exibição do imenso acervo de arte moderna da instituição, realizando diversas exposições itinerantes. Ao mesmo tempo, e principalmente a partir de fins da década de 1960, o museu dedicou-se a experiências expositivas que procuravam fomentar e legitimar a produção de jovens artistas brasileiros numa série de exposições anuais que ficaram conhecidas como Jovem Arte Contemporânea.

7 Nessa época notava-se a nível mundial que a nova realidade da prática artística exigia uma discussão e uma reformulação do papel dos museus. Em 1963, foi realizado o encontro anual do Comité Internacional para Museus e Coleções de Arte Moderna (CIMAM) ${ }^{1}$, um comité vinculado ao Conselho Internacional de Museus (ICOM). Este encontro contou com a participação de Walter Zanini, de outros diretores de museus e críticos de arte como Pierre Gaudibert (curador do Museu de Arte Moderna de Paris), Jean Cassou (fundador e curador do Museu Nacional de Arte Moderna em Paris) e René d'Harnoncort (curador do MoMA de Nova Iorque), que também estavam preocupados em orientar as suas práticas políticas e institucionais no sentido da construção de um museu 
de arte moderna e contemporânea como um "laboratório experimental" (Zanini 1964, s/ p). As discussões dirigiram-se no sentido da diferenciação entre os museus de arte antiga e os de arte contemporânea: foram discutidos tópicos relativos à apresentação das obras, à relação entre museu e artista, à constituição de acervos de arte contemporânea e moderna, entre outros.

No contexto da dupla função em que os museus de arte contemporânea teriam ao mesmo tempo de colecionar/conservar objetos de arte e de se dedicar à arte do presente, os museus deveriam procurar estruturar-se também como centros de pesquisa e de documentação. Dessa maneira não se poderia excluir a peculiaridade fundamental dos museus, nomeadamente a conservação e a exposição de objetos, nem tampouco o seu compromisso como plataforma crítica para a discussão da arte do presente (muitas vezes de caráter não-objetal, desmaterializada, processual e conceitual) e a sua relação com a política e a sociedade.

9 Os museus de arte moderna e contemporânea deveriam, portanto, atuar em duas frentes: na salvaguarda, conservação e exposição do seu acervo, procurando preencher as suas lacunas, expandi-lo e pesquisá-lo, e, ao mesmo tempo, atuar como museu-vivo, fórum de debates, laboratório de práticas artísticas experimentais, constituindo-se como espaço de reflexão crítica sobre arte e política.

10 No encontro realizado em 1963, Werner Hoffmann definia o museu como um centro vivo para as ideias contemporâneas, um local para a divergência e para a contestação, mais do que um centro de informação ou um arquivo. Noutras palavras: uma instituição que mais do que tranquilizar os espíritos deveria confrontar o Homem com as inquietações da sua própria existência (Zanini 1964, s/p).

11 Nesse mesmo encontro, Jean Cassou afirmava que a particularidade dos museus de arte moderna seria guardar os objetos de uma civilização presente, ou seja, objetos que ainda não tivessem sido legitimados pela História e pelo tempo (Zanini 1964). Essa peculiaridade poderia culminar numa abordagem interdisciplinar das obras apresentadas por esse tipo de museus, que poderia misturar peças de música, dança e literatura no seu acervo.

No caso da IX Conferência Geral do ICOM realizada em $1968^{2}$, Jean Cassou defendia que a arte numa sociedade capitalista fatalmente perderia o seu poder de negatividade e o seu potencial questionador, tornando-se apenas objetos voltados para o consumo, passíveis de absorção pelo mercado. Para o autor, o ato da criação artística continha sempre uma rejeição ao presente, e a criação artística entendida, em vários momentos, como subversiva. Essa noção de arte seria incompatível com o conceito de museu-templo e com as narrativas lineares da história da arte propagadas por esse tipo de instituição (Cassou 1968).

13 Em 1969, na conferência anual do CIMAM realizada em Bruxelas ${ }^{3}$, o professor Helmut Leppien afirmava: «Ou o museu muda, ou está morto» (Leppien 1969, s/p). A frase reflectia a preocupação do intelectual com as diversas manifestações artísticas que contestavam as funções tradicionais dos museus. De acordo o autor, os profissionais, os críticos e os intelectuais que ainda acreditavam na importância dos museus deveriam orientar as suas práticas para a transformação destes em locais mais adequados às atividades artísticas de então. No mesmo sentido, Gaudibert sugeria:

[...] La transformation du musée en un lieu d'échanges, de débats, de confrontations: ils s'agit soit dans les salles d'exposition, soit dans une salle polyvalente qui sert aux débats et aux activités complémentaires, de favoriser les échanges verbaux entre publics, créateurs et critiques [...] toutes ces pratiques ne 
veulent passé le ment être une adjonction quantitative d'activités complémentaires a une institution traditionnelle; elle visent a transformer les musées d'art modern, palais de consécration d'artistes' exposes, en un centre culture vivant, en un laboratoire plastique expérimental [...]. (Gaudibert 1969, s/p)

Muitas das ideias discutidas nos encontros organizados pelo ICOM foram, em diversos momentos, postas em prática durante a gestão de Zanini no MAC USP, principalmente na série de exposições Jovem Arte Contemporânea. Os convites que recebeu para participar em colóquios como delegado nacional do Brasil (Boletim de Informações 1967) reconheciam o carácter vanguardista da sua atuação na direção do museu e, mais do que isso, permitiram que fossem partilhadas referências, preocupações e propostas sobre a nova postura dos museus de arte moderna e contemporânea. Esses debates possibilitaram também a reflexão e a legitimação internacional do projeto de museu vivo implementado no MAC USP.

Neste sentido, as JACs, desde o seu surgimento em 1963, procuraram afirmar-se em oposição ao salão de belas-artes tradicional:

Os objetivos das exposições para jovens do Museu do Arte Contemporânea da Universidade de São Paulo são diversos daqueles do "salon" tradicional. Este visa ao recenseamento de extratos mais definidos e a sua consagração. Com o limite de idade em torno dos 35 anos, as mostras destinadas às gerações ascendentes voltamse para os estreantes já com a base mínima de valor criativo e para os que se encontram em evidente processo de afirmação. Provoca-se assim um confronto estimulador e em larga escala que permite conhecer novas problemáticas em jogo e conjeturas sobre seu futuro, embora se reconheça a instabilidade da pesquisa que caracteriza neste século essa etapa da evolução artística. (Zanini 1966, s/p)

No entanto, esta série de exposições até à sua quinta edição não escapou estruturalmente a um formato mais tradicional: limites de idade, nacionalidade, obras inscritas, júri de seleção e premiação. A radicalização dos objetivos, explicitados por Walter Zanini em 1966, aparecem de facto na sexta edição da mostra (1972), que a partir das sugestões de artistas, estudantes, intelectuais e críticos - dadas num debate no próprio museu - adotou um sistema de loteamento do espaço do museu e o sorteio entre artistas inscritos sem nenhuma restrição.

A sexta edição da JAC ocorreu no MAC USP entre os dias 14 e 28 de outubro de 1972 e tinha como objetivo, segundo consta no regulamento:

[...] apresentar largo confronto das iniciativas processuais da linguagem contemporânea com as suas diferentes cargas informacionais, conteúdos semânticos e motivações interdisciplinares [...]. O MAC procurará centralizar a VI JAC nas tendências artísticas contemporâneas que transferem a ênfase do objeto produzido para os processos de produção: arte do efêmero, arte sensorial e conceitual, arte ambiental, e outras opções criativas que nos dias atuais voltam sua atenção para os processos dinâmicos da atividade artística. (Regulamento VI JAC $1972, \mathrm{~s} / \mathrm{p})$ 


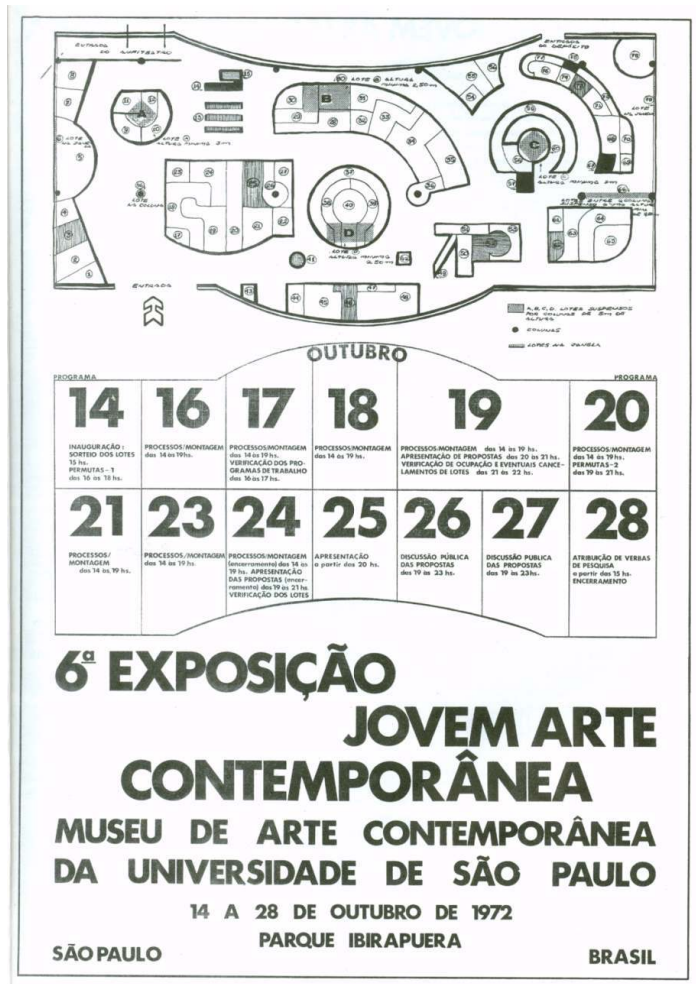

Fig. 1 - Cartaz da VI JAC, incluindo o calendário e a planta do museu com a distribuição em lotes. Arquivo MAC USP

Para o efeito foi organizado um calendário que compreendia no primeiro dia da exposição o sorteio dos lotes entre os inscritos, seguido de oito dias para a montagem dos trabalhos nos lotes, um dia para a apresentação pública das propostas, performances e happenings, dois dias para a discussão das propostas e um último dia para a atribuição de verbas para as pesquisas. $O$ cronograma da exposição também previa a verificação contínua da execução das propostas e da ocupação dos lotes pelos sorteados, bem como a permuta de lotes entre os participantes - no dia do sorteio e cinco dias depois. É importante ressaltar que a exposição se encontrava aberta ao público desde o dia do sorteio, incentivando a participação dos visitantes no processo artístico, a convivência com os artistas e a reflexão sobre a arte e o espaço do museu:

A possibilidade de confronto, colaboração, auxílio, permuta, construção ou destruição, além da discussão permanente entre os participantes, concretizou a autoria coletiva da exposição. Em pleno regime militar, realiza-se na exposição/ manifestação um exercício experimental de liberdade. Aboliu-se, assim, qualquer juízo de valor ou critério para a inclusão dos 120 sorteados, entre artistas e grupos. Tal processo parece desconcertante pelo caos que invade o ambiente asséptico do museu. 0 planejamento prévio dá lugar às decisões tomadas em comum acordo entre os participantes onde não se distingue artista de público. Não há um curador, e mesmo o poder executivo do diretor do museu é rebaixado. 0 museu redefine-se, assim, como um microcosmo do possível, e tem como horizonte a liberdade. Pelo contexto de exceção que se vivia no Brasil daqueles tempos, radicaliza-se nessa exposição um espaço público de participação. (Freire 2009, 40)

Inscreveram-se para a participação na mostra 210 artistas, entre brasileiros e estrangeiros. Figuravam nomes já reconhecidos dentro do circuito oficial, como Hélio Oiticica e Daniel Buren, ambos artistas não sorteados. Estavam entre os sorteados professores como Donato Ferrari e Nicolas Vlavianos e muitos artistas mais jovens, ainda 
estudantes. $O$ sorteio permitia a participação de qualquer pessoa e incentivava a formação de grupos e de equipas para uma participação coletiva. Entretanto, muitos lotes ficaram desocupados e foi realizado um segundo sorteio, que redistribuiu os 13 lotes cuja ocupação não se havia verificado.

Os 84 lotes tinham dimensões diversas e foram desenhados e agrupados em 10 blocos principais de formas também diversificadas, por vezes circulares, arredondadas e retangulares. Dentro desses blocos, alguns lotes possuíam "encaixes" entre si, outros tinham formas orgânicas que favoreciam uma integração ou um diálogo entre as propostas a serem realizadas, ou mesmo a produção coletiva entre os artistas no sentido da convivência e da problematização do próprio ambiente da exposição.

21 Alguns lotes tinham um formato ou uma posição muito peculiar, mais isolado - por exemplo, os lotes 13 e 78; em volta de uma coluna, ou sendo até a própria coluna no caso do lote 16. O desenho irregular da maioria dos lotes tornou-se, como se verá mais adiante, foco das discussões e objeto dos trabalhos desenvolvidos por vários dos artistas participantes.

Muitos artistas que não haviam sido sorteados juntaram-se a outros, formando equipas de trabalho coletivo, ou compraram e trocaram lotes, como é o caso de Gabriel Borba, que havia sido recusado nas duas edições anteriores da JAC e não havia sido sorteado para a sexta edição, mas acabou recebendo a doação do lote 9. Nesse lote, o artista desenvolveu a proposta À Brecht - A Exceção e a Regra em que reuniu toda a documentação produzida pela burocracia institucional do MAC, discutindo os circuitos dos documentos que legitimavam ou não um trabalho artístico e o papel da própria exposição JAC dentro desse sistema.

o Grupo Conceitual formado por Lydia Okumura, Genilson Soares e Francisco Iñarra, realizou em diversos lotes ${ }^{4}$ as propostas enviadas por artistas como Arthur Luiz Piza, Erika Steinberger, Sérvulo Esmeraldo, Jaques Castex e Jannis Kounellis que se inscreveram para participar da exposição, mas como viviam no exterior não puderam estar presencialmente no evento. As propostas enviadas demandavam os mais diversos esforços por parte do grupo, nomeadamente encontrar uma pianista que pudesse tocar uma peça durante todo o tempo da exposição (obra de Kounellis), encontrar um motor de um camião velho (obra de Erika Steinberger) ou pintar painéis imensos (obras de Castex e Esmeraldo). 


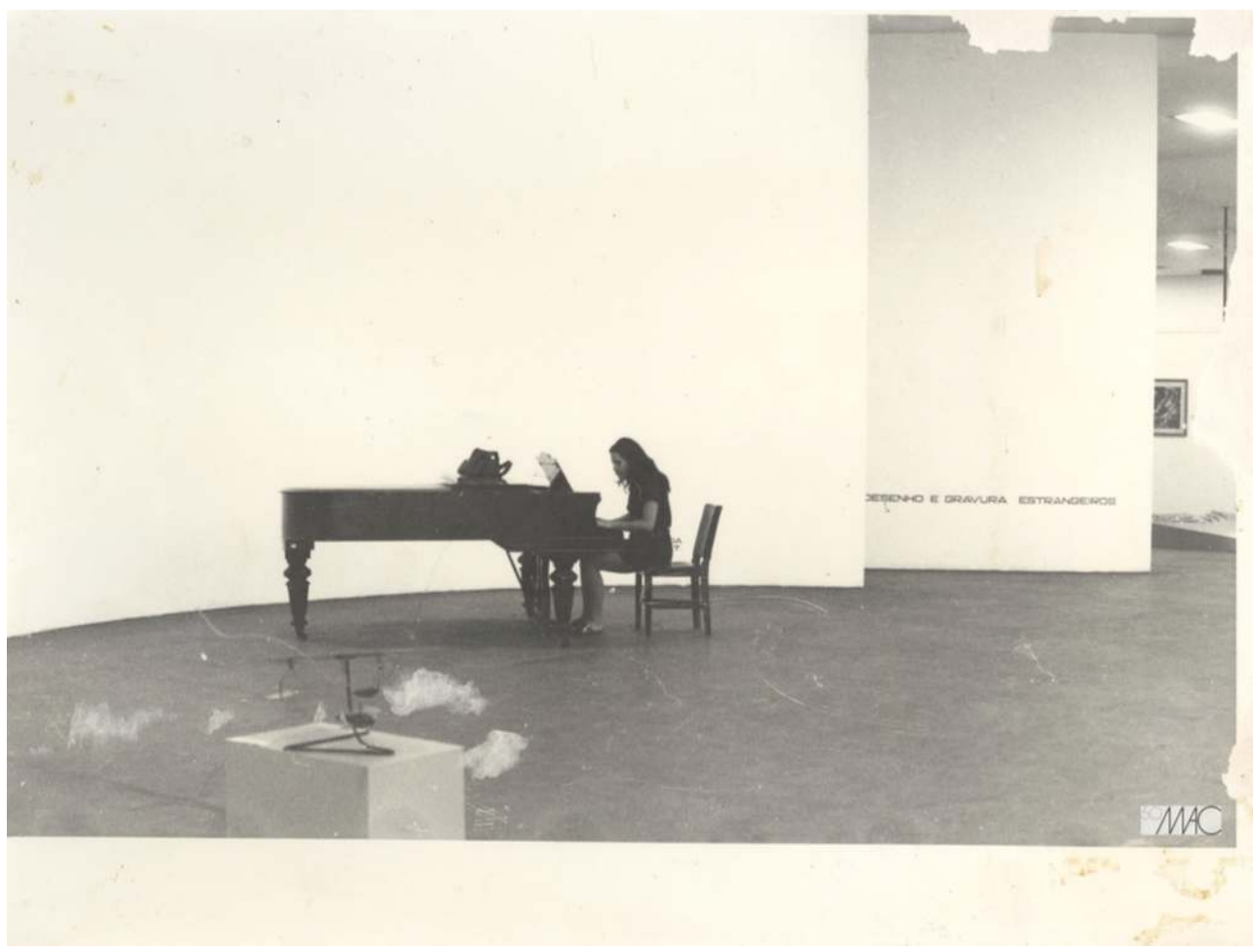

Fig. 2 - Proposta Incluir os Excluídos de Lydia Okumura, Genilson Soares e Francisco Iñarra. Execução da obra da Janis Kounellis. VI JAC, 1972

Fotógrafo: Gerson Zanini, Arquivo MAC USP

24 Cabe ainda destacar a participação do próprio público da exposição na execução e elaboração das propostas, como foi o caso do trabalho desenvolvido com a ajuda de alunos do ensino secundário da Escola Estadual Martins Pena no lote de número 26 ocupado por Jacira de Barros Quintas del Corso. Juntos criaram uma instalação no lote em formato de corredor ligado a um círculo com uma coluna, que exigia a participação do espectador para a sua sensibilização e tomada de consciência a respeito das questões relativas à vida e à morte, à renúncia, à alienação e à guerra:

Integrando a música ao ambiente, exteriorizando suas expressões nas paredes ou no próprio alumínio deformante, ou apenas entrando no corredor para rodear uma coluna e sentir as deformações ou alçar os olhos para o teto, o público participa pelo reflexo da figura, pela escolha da música, pela direção dos olhos, pelo sentimento externado, do projeto por nós iniciado, mas só então acabado. (Corso $1972, \mathrm{~s} / \mathrm{p})$. 


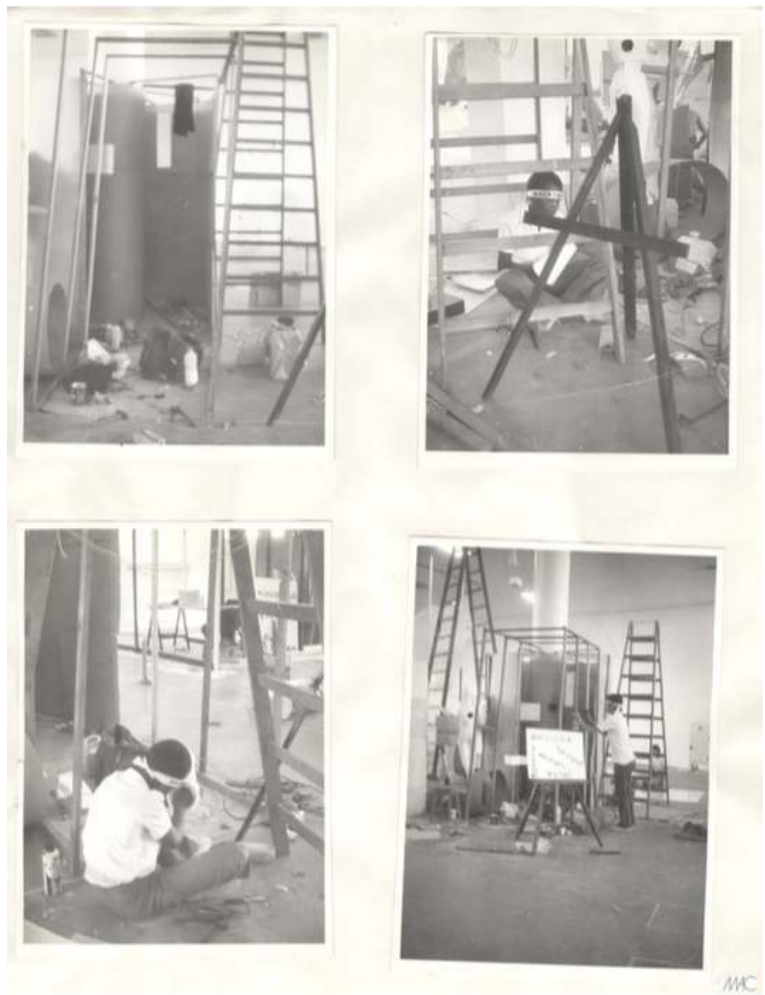

Fig. 3 - Montagem do lote 26, VI JAC

Fotógrafo: Gerson Zanini, Arquivo MAC USP

Walter Zanini, no catálogo da mostra, descreve a exposição como uma manifestação que compartilha do espírito do tempo demonstrado em outras exposições, como a $V$ Documenta, realizada também no ano de 1972. A exposição com curadoria de Harald Szeemann contava com a forte presença de um projeto e de um posicionamento individual da figura do curador, na qual a exposição em si se tornou uma grande obra. A VI JAC, embora não tivesse a figura do curador, apenas impôs algumas regras e limitações para a participação dos artistas, também se tornou uma espécie de obra coletiva:

Não se tratava de uma 'exposição' para ser vista em cinco minutos ou numa noite solene de inauguração; era um tipo de manifestação para ser acompanhada na sua vivência, no seu crescimento diário, no diálogo com uns e com outros, na procura da compreensão de cada atitude, de cada comunicação [...]. Até a trivialidade de certas propostas ganhava no contexto uma dramaticidade raramente transmitida por uma exposição. Foi uma mostra duramente amarrada a existência diária, válida, autêntica, impressionante em sua verdade. (Zanini 1972, s/p)

A proposta desenvolvida por Szeemann para a V Documenta, intitulada Questioning Reality, Image Worlds of Today, procurava confundir e questionar a própria realidade social, da arte e da arte como representação, através da mistura entre objetos ordinários, denominadas iconografias sociais - relacionados com a cultura popular, com a política, o kitsch, a arte sacra, etc. - e trabalhos de artistas conceituais, performers e hiper-realistas (Derieux e Aubart 2007, 91).

A quinta edição da Documenta foi primeiramente pensada como um grande evento de 100 dias de duração. A exposição acabou sendo concebida como uma vasta coleção de "coisas" do universo visual contemporâneo como se fosse uma versão concentrada da vida em forma de exposição. Esse conceito é semelhante ao dos primeiros gabinetes de curiosidades do século XVIII, que se propunham como microcosmos do mundo visível, 
reunindo objetos de arte e antropológicos, religiosos e de interesse das ciências naturais. A exposição propunha-se a ir além dos limites da arte dita "real" para discutir o significado da representação na sociedade contemporânea, na qual os média exerciam um papel de "duplicar o mundo", igualando realidade e representação.

A mostra incluía ainda um cronograma para a realização de muitos happenings e performances, entre os quais se destaca o Bureau of Direct Democracy, de Joseph Beuys, no qual o artista discutia temas políticos e sociais com os visitantes durante todo o período da exposição. Pode-se dizer que, assim como a sexta JAC, a $V$ Documenta foi uma exposição intimamente relacionada com o tecido político e social do seu tempo. Isso verificou-se tanto nos trabalhos dos artistas apresentados, como na própria forma de conceção e organização da exposição. Ambas foram pensadas sem se basearem na contemplação passiva do espectador, afirmando-se a partir de conceitos que dizem respeito à arte como prática quotidiana e à desmaterialização e efemeridade do objeto ou gesto artístico.

No contexto pós-1968, Szeemann advogava uma postura tida como paradoxal, na qual a relação entre a arte e a vida poderia acontecer dentro do espaço institucional. Ou seja, contestava-se o papel da instituição e, ao mesmo tempo, a sua reafirmação. De acordo com o curador, a única instituição capaz de dar sentido às práticas subversivas das tendências mais contemporâneas seriam os museus. Essa ideia de que as novas tendências da arte contemporânea ou pós-moderna poderiam moldar um novo modelo de instituição era oposta à ideia mais utópica defendida por Pierre Restany durante o maio de 68, ou seja, a de que a arte deveria ganhar às ruas, abandonando de vez os museus.

De acordo com Restany (citado por Schroeder 2011, 90) o artista de vanguarda deveria pautar a sua postura em relação ao sistema da arte a partir do conceito de anti. 0 antiartista seria aquele que rejeitava as formas tradicionais da arte e que, portanto, deveria construir uma anticarreira pautada pelos conceitos de antiforma e de anticódigo. Em oposição ao artista que fabricava objetos que poderiam ser interpretados a partir de um código cultural dominante, o antiartista definiria situações que conclamam o espectador à participação, num gesto de contestação à cultura e ao sistema vigente, ou seja, aquilo que no quadro "carreira" era o ápice da consagração, tornava-se o máximo do comprometimento burguês. O ápice da consagração na "anticarreira" consistia em recusar-se a participar nas Bienais do sistema. $\mathrm{O}$ antissistema tinha a sua hierarquia de recusa própria (Schroeder 2011, 90).

31 Sobre a gestão de Walter Zanini no MAC USP, Restany comentava:

Faz-se necessário sublinhar o papel de Walter Zanini, diretor do Museu de Arte Contemporânea da Universidade de São Paulo, que conseguiu conciliar as exigências de duas gerações de uma só vez (...) sua inquietude aliada a um profundo interesse pelas pesquisas dos jovens sempre me pareceu sintomática de uma tomada de consciência. (Restany, citado por Freire 1999, 59)

32 Nessa edição da Documenta, um fator que concedeu grande liberdade a Szeemann foi a sua autonomia em relação ao conselho administrativo, o que evitou preocupações e obrigações burocráticas, e garantiu-lhe a possibilidade de expressar a sua visão individual e trabalhar com a sua própria equipa. Tal como Szeemann, Zanini também teve liberdade suficiente para por em prática uma exposição experimental, focando as necessidades dos novos artistas e dar ênfase aos trabalhos processuais. A semelhança entre as posturas de Szeemann e de Zanini também se encontram no entendimento dos museus como locais de possíveis experimentações capazes de darem sentido às práticas artísticas de então. 
Assim como a Documenta de Szeemann, a realização da sexta JAC provocou a entrada de objetos quotidianos, questionando a realidade da arte e dos novos processos artísticos, sendo que muitas das obras apresentadas incorporavam elementos e objetos de uso diário. A este propósito pode-se citar a ocupação do lote 8 e do lote 15 . 0 lote 8 foi ocupado por Auresnede Stephan, Marcia Bussab e Luiz Kawal Vasconcelos que incluíram objetos ordinários e elementos alheios ao meio da arte, como restos de frutas, uma tesoura, fita adesiva, ilustrações, entre outros, questionando os meios, os materiais e os ambientes da arte à época. No lote 15 foi desenvolvida a proposta Boi Encantado por Paulo Fernando Novaes Correa, apresentando um pedaço de carne de boi sobre uma estrutura de fórmica, que entrou em processo de putrefação no decorrer da exposição e acabou por ser retirada, embora $80 \%$ dos artistas participantes assinassem um abaixo-assinado para o retorno da obra, uma vez que fazia referência ao entendimento da arte como processo e à relação entre a arte e a vida.

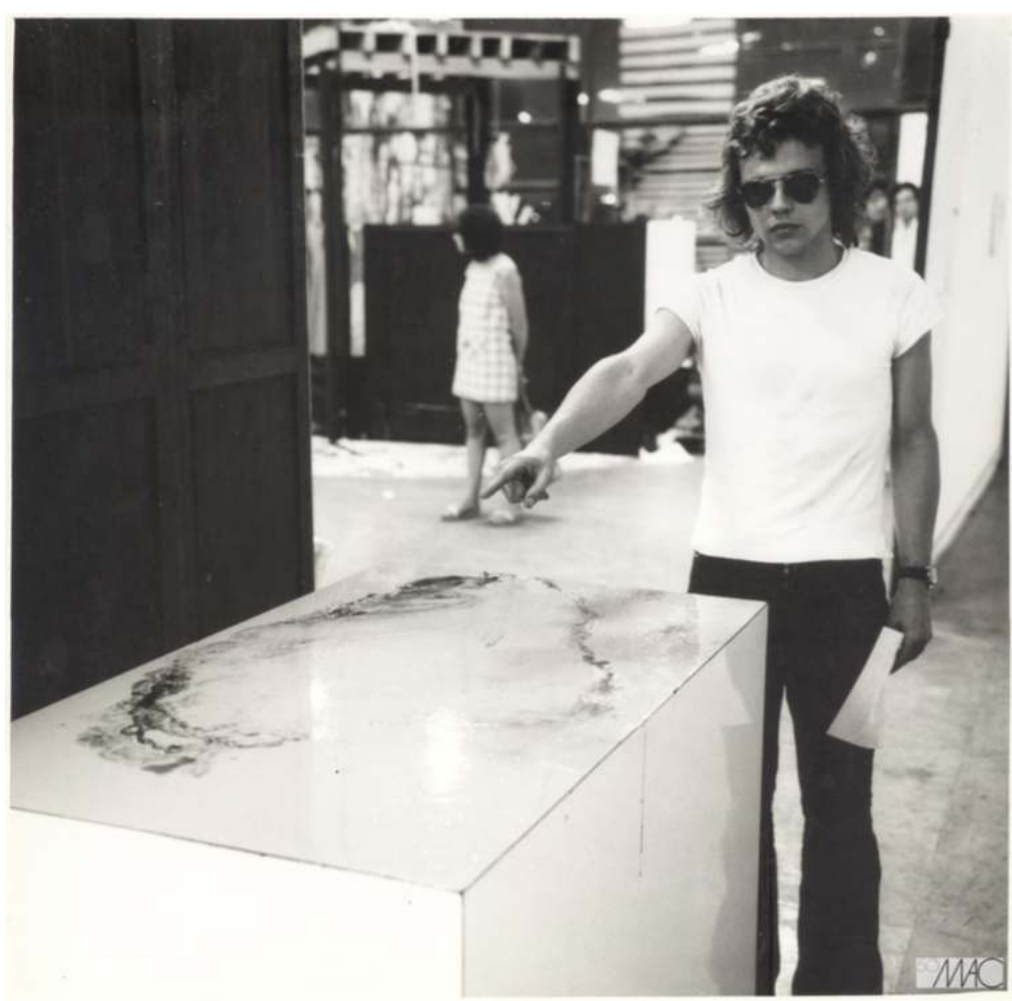

Fig. 4 - Ocupação do lote 15 por Paulo Fernandes Novaes Correa com a proposta Boi Encantado, VI JAC, 1972

FOTÓgRAFO: GERSON ZANINI, ARQUIVO MAC USP

O artista, sobre a sua obra e a experiência na exposição, comentava:

Interessava ao artista demonstrar unicamente a intimidade de um processo natural. A analogia é óbvia. A carne deveria estar absolutamente insuportável no dia 25 . E é óbvio que a putrefação não se interrompeu com a simples remoção da obra. Ele estará apodrecendo em outro lugar.

É de se ressaltar a beleza da carne. Principalmente se observando o processo criativo que ela traz em si, em processo inevitável, e oportunamente 'atual'. Poderia falar ainda que nessa $6^{\mathrm{a}} \mathrm{JAC}$, o que mais importaria era a execução, só ela esteve presente nessa $1^{a}$ parte do meu trabalho. Um trabalho que foi, e continuará, feito unicamente a partir do momento. Cada momento determinou uma situação, uma reação diante da obra. (Correa 1972, s/p) 
A realização de uma manifestação/exposição com uma estrutura que permitia uma grande liberdade de criação e de provocação, e que favorecia o encontro, o debate e o pensamento crítico é significativo se considerarmos o contexto altamente repressivo e o clima de terror vigente no Brasil, desde dezembro de 1968. O Museu, nesse período afirmava-se como um espaço de resistência: ao mercado, ao valorizar as formas de circulação alternativas e os trabalhos feitos com materiais precários e ordinários; a repressão, permitindo encontros entre professores, intelectuais, artistas e críticos; e de resistência ao museu tradicional.

Ainda em julho de 1972, um pouco antes da realização da VI JAC, Zanini publicava um texto chamado $O$ Museu e o Artista, no qual aprofundava algumas questões sobre o relacionamento entre a instituição e as experimentações artísticas. Zanini descreveu a «forma revolucionária de participação ativa e direta no contexto criador» como um novo papel dos museus de arte contemporânea. O conceito fica mais claro ao observarmos certos aspetos da VI JAC. Nesta exposição, o Museu propunha-se a atuar durante o processo de criação, abrindo o seu espaço aos artistas e, ao mesmo tempo, impondo alguns limites (lotes, calendário, entrega de propostas) para a sua atuação.

[...] o Museu obviamente não poderá guardar o distanciamento de outrora, permanecendo como um meta júri à espera dos fatos. A estrutura do museu deverá possibilitar os meios para a sua realização enquanto órgão envolvido no próprio ato da criatividade. Seus objetivos serão os do proporcionar recursos ambientais e instrumentais aos artistas, de converter-se em núcleo de energia que permita confrontos sistemáticos entre os artistas e relacionamentos dialéticos dos artistas com estudiosos e o público em geral e de manifestar-se como centro dinâmico do ponto de vista dos múltiplos aspetos da documentação. (Zanini 1972, s/p)

Pode-se dizer que a experiência da VI JAC foi singular e fundamental para a constituição de um museu vivo, fórum e laboratório, no sentido em que se abriu totalmente para o diálogo com os artistas, estudantes e intelectuais. Isso possibilitou a construção inédita e experimental de um museu enquanto um local de encontros, de crítica, de resistência e de debate, através do encorajamento da incipiente produção conceitual nas suas múltiplas manifestações. Segundo Waldemar Cordeiro, na sexta VI JAC:

O modelo comunicativo simula as características consideradas essenciais do sistema real de acordo com uma premissa crítica assumida [...]. A "obra" objeto físico da representação - totem da sociedade de consumo - é substituída por eventos programados de acordo com estratégia última [...]. A indústria do entretenimento invadiu a chamada cultura superior e a arte também, tornando tudo muito elementar, fluível sem esforço e principalmente comprável. (Cordeiro 1972, s/p)

Desta maneira, a exposição constituiu-se como uma plataforma crítica para a reflexão sobre o lugar do museu, da arte e do artista na sociedade de consumo, incentivada por uma ditadura desenvolvimentista e um território de liberdade (Freire 2009) em contexto repressivo. De acordo com Amelia Toledo Amorim, num texto publicado no próprio catálogo da VI JAC:

[A JAC-72] é um resumo crítico das contingências em que vivemos, que as representa de forma a aguçar as nossas reações e oferece uma situação privilegiada, onde as consequentes reações encontram abrigo [...]. Portanto, o que se chamou depois de "confusão" resultante tenha sido o retrato do nosso estado de perplexidade. [...] A confortável ordem estética das aparências, almejada por alguns, seria um retrato falso ou superficial da situação do mundo. E, afinal, pretende-se ou não que o artista represente sua visão de mundo? [...] De certa maneira, o MAC funcionou como um enorme palco para um psicodrama em que à representação acrescentaram realizações. A meu ver, a JAC-1972 é portanto, um documento 
significativo de uma situação. Estimulou. Incomodou. Serviu [...]. (Amorim 1972, s/

p)

39 A artista refere-se, principalmente, às críticas veiculadas na imprensa sobre a exposição.

A incompreensão, a indignação e o juízo crítico negativo foram as tónicas que determinaram as notícias sobre a VI JAC. Olney Krüse, na revista Veja, comentava sobre a noite do dia 24 de outubro, em que o período de execução das propostas foi encerrado e se apresentavam algumas performances:

$\mathrm{Na}$ última quarta-feira, a noite, as 'obras' estavam prontas, e expostas. Quem foi, viu. Isso: galinhas enforcadas, ovos quebrados, tartarugas e galinhas vivas, miolos de boi protegido numa redoma, coelhos (vivos) pintados de roxo, azul, amarelo. $\mathrm{E}$ lixo, muito lixo espalhado em vários lotes: terra suja, cabelos, papéis amassados, gritos gravados, um piano desafinado, carne de boi cheia de moscas. (Kruse 1972, s/ p)

40 As "obras" às quais o crítico se refere são, provavelmente, as dos lotes 1, ocupado por Roberto Smith e por Paulina Rabinovitch, do lote 3 ocupado por Estevam Sunao Takyi e a carne de boi no lote 15. O pianista desafinado fazia parte da proposta Incluir os Excluídos, do Grupo Conceitual.

41 No lote 1 os artistas fizeram uso do deslocamento de "objetos" do quotidiano procurando estabelecê-los como objetos culturais - atribuindo-lhes outros níveis de significado. Para isso colocaram 25 galinhas dentro do lote de formato de triedro. Essa forma tornava-se tridimensional a partir de uma rede presa no teto, que também servia para conter os animais ali presos. Para estes artistas, o triedro representava uma quebra no espaçotempo que permitia a transformação de elementos da natureza em elementos culturais. 0 trabalho destes artistas também se referia, metaforicamente, à ditadura militar e ao cerceamento das liberdades.

A proposta de Pedro Lopes Soares e de Toshibume Nakano, executada no lote 47, tal como a proposta do lote 1, também pode ser entendida como uma metáfora para a situação política do Brasil, que vivia sob a censura da ditadura militar. Os artistas apropriaram-se de anões de jardim e montaram no estreito lote retangular uma cena na qual a Branca de Neve aparecia engaiolada sobre um banquinho e os anões estavam dispostos em volta, calados, assistindo à cena passivamente. Na proposta publicada no catálogo, a dupla apontava a importância do gesto artístico de deslocar objetos do quotidiano, dando-lhes novos significados. Figura entre aspas o que pode ser o título da proposta: "Quando o quintal é palco de uma tragédia representada pela Branca de Neve e assistida pelos sete anões" (Nakano e Soares 1972, s/p). No lote 3 haviam sido dispostos ovos com o objetivo de investigar a relação entre o objeto e o observador. Na proposta, publicada no catálogo, o artista explicava (Takyi 1972, s/p):

ovos

Conotações: Fragilidade, Interferência, Consumo, Tensão, Sujeira, etc.

Fatores levados em consideração:

a) $\mathrm{O}$ fato de ser uma realidade de consumo;

b) o condicionamento dos indivíduos que os leva a assumir determinados comportamentos diante de determinados fatos;

c) Uma determinada classe de indivíduos que tem acesso a determinada cultura. 


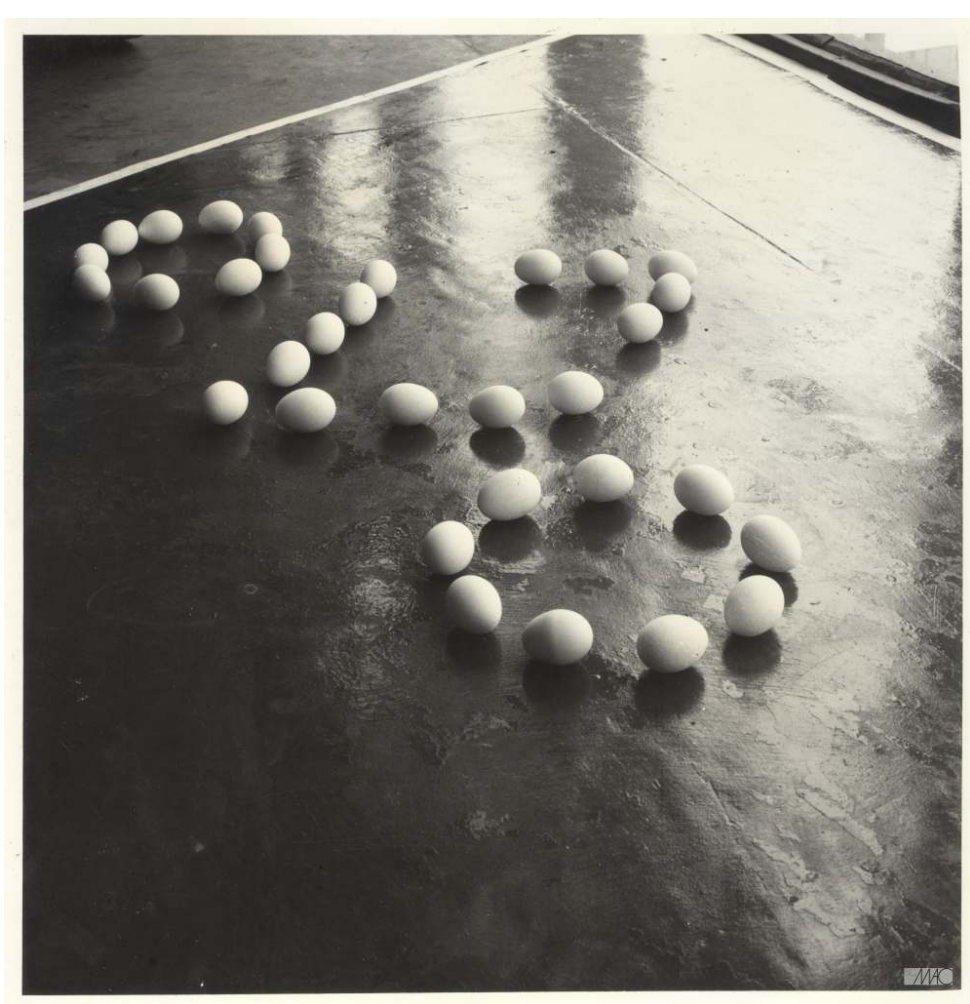

FIg. 5 - OCUPAÇÃo dO LOTE 3 POR ESTEVAM SUNAO TAKYI, VI JAC, 1972 FOTÓgRAFO: GERSON ZANINI, ARQUIVO MAC USP

Os coelhos faziam parte da proposta do lote 28, doado por Moacir Schnapp a Aldir Mendes de Souza e a Rubens Coura. $O$ trabalho estruturou-se como uma crítica à organização da própria exposição em lotes. A dupla usou os coelhos pintados como metáforas para falar dos artistas presentes na exposição:

Expusemos coelhos vivos, pintados de cores diversas (com tintas hipoalergênicas), que comiam, bebiam e se moviam em gaiolas negras, sobre pilares igualmente negros. Os coelhos engaiolados representavam os artistas da exposição, que, humildes como esses animais, aceitaram o sistema de lotes sorteados e limitados. (Schnapp et al. 1972, s/p)

$44 \mathrm{Na}$ proposta que foi entregue para discussão, os artistas apresentavam ainda algumas conclusões a respeito da proposta executada no seu lote, entre estas estavam:

4 - O artista deve ser sensível a sua época para poder retratá-la com meio correspondentes a ela.

6 - Os coelhos coloridos oferecem um espetáculo cinético de efeito interessante na exposição.

7 - Estes animais são bons símbolos de humildade e complacência ante ao esquema 'imposto' pela exposição.

8 - Os coelhos soltos soa a ideia de quebra dos limites entre os lotes, pois eles circulam por toda a exposição sem limite de áreas. (Schnapp et al. 1972, s/p)

Para justificar tamanho grau de experimentalismo e a mudança radical no ambiente museológico durante o período da VI JAC, Zanini recorreu às discussões ocorridas nos encontros organizados pelo ICOM:

Por ocasião das reuniões do ICOM, têm sido estudados os museus sob vários ângulos, inclusive o tradicional, numa procura de solução para nova estrutura. Uma das conclusões foi a de que a par da posse de coleções de obras adquiridas, doadas ou expostas temporariamente, o museu de arte contemporânea precisaria ter uma 
parte ativa de ligação com o mundo exterior [...]. Nos últimos tempos, o museu, que era apenas um local de guarda de obras, passou a ter uma atuação ativa no desenvolvimento cultural da sociedade. Estamos ainda num período de transição, no entanto. Nos tempos atuais, não podem mais ser estáticos. [...] Isto posto sobre o que deveria ser um museu de arte contemporânea, não poderíamos deixar de cogitar numa mudança de arcaica modalidade de expor trabalhos escolhidos por um júri, nem sempre bem capacitado, o que tem acarretado inúmeros problemas. Até agora, não foi possível encontrar uma fórmula para sanar essa falha. $\mathrm{O}$ que o Museu de Arte Contemporânea de São Paulo pretendeu ao reformular o planejamento da presente JAC, foi justamente fazer uma tentativa nesse sentido. Não está preocupado como sucesso imediato. A exposição tem o caracter experimental para poder ser talvez um ponto de partida para a reformulação dos juris. (Zanini 1972, s/ p)

Em defesa da estrutura da exposição, criticada por alguns artistas que consideraram limitadora a experiência do loteamento do museu, Zanini lembrava que os lotes haviam sido sorteados para que todos pudessem ter oportunidades iguais de participação e não se submetessem aos escusos critérios dos júris dos salões tradicionais. Além disso, os lotes podiam ser redistribuídos e trocados ao gosto dos participantes no decorrer da exposição. E acrescentava:

[...] o artista teria de 'criar' uma forma de arte adaptável ao lote recebido, o que daria a oportunidade de uma 'criação' espontânea, imprevista por vezes, com o aproveitamento do espaço recebido. Isto obrigou $o$ artista a sair do condicionamento do atelier ou da escola de arte. Além disso, ele teria que trabalhar ao lado de outros artistas, numa troca profícua de ideias que poderiam redundar em novas soluções inesperadas. O público terá parte importante porque poderá participar, assistindo aos trabalhos e até oferecendo sugestões, ou críticas. (Zanini $1972, \mathrm{~s} / \mathrm{p})$

No que diz respeito à historiografia da arte contemporânea, em que o júri e/ou o curador assumem o papel de definir quem deve ou não entrar na narrativa institucional oficial proposta pela instituição, o MAC USP ao propor o sorteio de lotes, ao encorajar o desenvolvimento de propostas em contraposição à colocação de obras prontas e ao abolir o prémio final, afirmou novamente o seu papel político e social durante a ditadura militar. Ou seja, constituir um local de liberdade para manifestações artísticas, para a pesquisa e para a crítica. Assim, o museu afirmou-se como plataforma crítica para a reflexão sobre as práticas museológicas no contexto da própria instituição, mas também no âmbito das práticas sociais e políticas desse período.

Pode-se dizer que no caso da VI JAC, a exposição em si foi mais significativa do que as obras, porque materializou as contradições e os questionamentos do campo artístico, através do sistema de loteamento e na relação absolutamente inovadora empreendida entre artistas e instituição. A convocação de artistas para trabalharem no museu durante o período da exposição, a publicação dos seus textos no catálogo, o sorteio de lotes e a não hierarquização das obras expostas foram atitudes que se converteram num gesto político de resistência e de contestação. 


\section{BIBLIOGRAFIA}

Altshuler, Bruce. 2008. Salon to Biennial: Exhibitions that Made Art History. London: Phaidon.

Amorim, Amélia Toledo. 1972. “Meu Ângulo de Observação sobre a JAC 1972.” In 6 $6^{\underline{a}}$ Jovem Arte Contemporânea [catálogo de exposição], 10. São Paulo: Universidade de São Paulo, Museu de Arte Contemporânea.

Boletim de Informações. 1967. Dossiê ICOM/AMAB, Pasta 0134/003, Arquivo MAC USP, 20 de novembro.

Cassou, Jean, ed. 1968. Art and Confrontation: The Arts in the Age of Change. Greenwich: New York Graphic Society.

Cordeiro Waldemar. 1972. "JAC 1972 Modos e Modelos." In 6 ${ }^{a}$ Jovem Arte Contemporânea [catálogo de exposição], 8. São Paulo: Universidade de São Paulo, Museu de Arte Contemporânea.

Correa, Pedro Fernandes Novaes. [1972]. "Proposta do Lote 15." Dossiê VI Jovem Arte Contemporânea . Pasta 0102/015, Arquivo MAC USP.

Corso, Jacira Barros Quintas Del. 1972. “Proposta do Lote 26." In 6ª Jovem Arte Contemporânea [catálogo de exposição], 43. São Paulo: Universidade de São Paulo, Museu de Arte Contemporânea.

Derieux, Florence, e François Aubart. 2007. Harald Szeemann: Individual Methodology. Zurich: JRP Ringier.

Freire, Cristina. 1999. Poéticas do Processo: Arte Conceitual no Museu. São Paulo: MAC, Universidade de São Paulo e Iluminuras.

Freire, Cristina. 2009. “Território de Liberdade: Um Museu de Arte Contemporânea Durante a Ditadura Militar no Brasil.” In Já! Emergências Contemporâneas, organizado por Orlando Maneschy, e Ana Paula Felicissimo de Camargo Lima. Belém: Editora Universitária EDUFPA.

Gaudibert, Pierre. 1969. “Les Activités Complémentaires.” Dossiê ICOM/AMAB. Pasta 0134/007. Arquivo MAC USP.

Kruse, Olney. 1972. “Lixo, Galinhas, Miolo de Boi: Uma Exposição de Arte.” Revista Veja, 28 de outubro.

Leppien, Helmut. 1969. "Comunicado Interno 2 AMAB sobre o Colóquio do CINAM - ICOM Bruxelas/dez/69.” Dossiê ICOM/AMAB, pasta 0134/007, Arquivo MAC USP.

Nakano, Toshibume, e Pedro Lopes Soares. "Data Proposta do Lote 47." In 6 Jovem Arte Contemporânea [catálogo de exposição], 48. São Paulo: Universidade de São Paulo, Museu de Arte Contemporânea.

Okumura, Lydia. 2011. Entrevista conduzida pelo Grupo de Estudos em Arte Conceitual e Conceitualismos no Museu (GEACC-CNPq) em dezembro de 2011, no Museu de Arte Contemporânea da Universidade de São Paulo. Material não publicado.

Regulamento VI JAC. 1972. Dossiê VI Jovem Arte Contemporânea. Pasta 0101/002, Arquivo MAC USP. 
Schnapp, Moacir, e Rubens Coura. "Data Proposta do Lote 28." In $6^{\underline{a}}$ Jovem Arte Contemporânea [catálogo de exposição], 43-44. São Paulo: Universidade de São Paulo, Museu de Arte Contemporânea.

Schroeder, Caroline Saut. 2011. “X Bienal de São Paulo: Sob os Efeitos da Contestação.” Dissertação de Mestrado em Artes Visuais, Escola de Comunicações e Artes, Universidade de São Paulo.

Soares, Genilson. 2011. Entrevista conduzida pelo Grupo de Estudos em Arte Conceitual e Conceitualismos no Museu (GEACC-CNPq) em dezembro de 2011, no Museu de Arte Contemporânea da Universidade de São Paulo. Material não publicado.

Takyi, Estevam Sunao. "Proposta do Lote 3." In 6 $6^{\underline{a}}$ Jovem Arte Contemporânea [catálogo de exposição], 33. São Paulo: Universidade de São Paulo, Museu de Arte Contemporânea.

Zanini, Walter, 1964. "Diretor do MAC Explica Arte Brasileira em Paris." A Gazeta Esportiva, 22 de fevereiro.

Zanini, Walter. 1966. “Gerações que Ascendem.” O Estado de São Paulo, 8 de janeiro.

Zanini, Walter. 1972. "Novas Potencialidades." In 6oำvem Arte Contemporânea [catálogo de exposição], 4-7. São Paulo: Universidade de São Paulo, Museu de Arte Contemporânea.

\section{NOTAS}

1. Realizado em Paris, entre 3 e 9 de outubro, sobre o tema "Problemas nos Museus de Arte Moderna".

2. Realizado em Munique e Colónia, na Alemanha, em agosto de 1968.

3. Conferência anual do CIMAM realizada em Bruxelas, Bélgica, entre os dias 9 e 12 de dezembro de 1969, sob o tema "Museus de Arte Moderna e a Sociedade Contemporânea".

4. O grupo ocupou inicialmente o lote de número 50, que foi concedido a Lydia Okumura por sorteio. Segundo os depoimentos de Genilson Soares e Lydia Okumura, em entrevista concedida à autora em dezembro de 2011, alguns lotes que haviam sido "abandonados" no decorrer da exposição serviram de espaço para a execução da proposta do grupo, que não caberia num só lote.

\section{RESUMOS}

Este artigo propõe uma reflexão sobre a exposição VI Jovem Arte Contemporânea, realizada em 1972 no Museu de Arte Contemporânea da Universidade de São Paulo (Brasil). São analisadas as estruturas inovadoras em que esta exposição se organizou, ou seja, a partir da construção da ideia de um museu-laboratório e também de acordo com o contexto político e social mais amplo, traçando dados comparativos com a exposição Documenta de 1972, paradigmática neste período, e os debates organizados pelo Conselho Internacional de Museus (ICOM). Para este efeito, tomou-se como base documental os textos de época elaborados pelos próprios artistas que participaram na mostra e no catálogo da exposição. A exposição VI Jovem Arte Contemporânea foi um importante marco entre as exposições realizadas no museu durante a década de 1970, colocando em prática 
as discussões sobre o estatuto da arte contemporânea e a importância de um museu-laboratório, realizadas dentro do próprio museu e também a nível internacional, propondo uma nova forma de pensar o fazer crítico na própria instituição direcionada para a arte moderna e contemporânea.

This article aims to discuss the exhibition VI Jovem Arte Contemporânea (Young Contemporary Art), which took place in 1972 at the Museu de Arte Contemporânea da Universidade de São Paulo (Brazil). The analysis considers the way in which the exhibition was conceived and organized, in the context of the museum as a laboratory, and also the wider political and social context, establishing comparisons with the exhibition Documenta, from the same year, and the debates organised by the International Council of Museums (ICOM). This discussion is based on documental resources, namely the texts written by artists and the museum's directors who participated in the exhibition and in making the catalogue. The exhibition Young Contemporary Art was an important landmark among the exhibitions that took place in the Museum during the 1970s, generating discussions on the status of contemporary art and the importance of a laboratory-museum. Such discussions happened both in the Museum and at an international level, proposing a new way of thinking about the praxis of criticism inside the institutions that deal with modern and contemporary art.

\section{ÍNDICE}

Keywords: history of exhibitions, contemporary art, art exhibitions

Palavras-chave: Museu de Arte Contemporânea da Universidade de São Paulo, história das exposições, Walter Zanini, VI Jovem Arte Contemporânea, arte contemporânea, exposições de arte

\section{AUTOR}

\section{HELOISA OLIVI LOUZADA}

Bacharel em História (2010) e mestre em Estética e História da Arte (2013) pela Universidade de São Paulo. Foi membro do Grupo de Estudos de Arte Conceitual e Conceitualismos no Museu (GEACC) - Conselho Nacional de Desenvolvimento Científico e Tecnológico (CNPq) e desenvolveu pesquisa sobre a arte conceitual no museu e sobre a história das exposições.

helouzada@gmail.com 